\title{
REVOLUÇÃO CIENTÍFICA E CONDIÇÕES DE POSSIBILIDADE DA PSICANÁLISE: SOBRE A PRESENÇA DE HUSSERL EM “A CIÊNCIA E A VERDADE"1
}

João Geraldo Martins da Cunha ${ }^{2}$

Léa Silveira ${ }^{3}$

\begin{abstract}
RESUMO: Em A ciência e a verdade, um dos textos da coletânea Escritos publicado pela primeira vez em 1966, J. Lacan formula uma tese de ampla repercussão em sua teoria: afirma que o sujeito da psicanálise é o sujeito da ciência moderna. Situa isso no registro de uma necessidade de reconhecer quais teriam sido as condições de possibilidade do tipo de discurso que se inaugura com S. Freud e remete agora sua análise, que vinha se detendo em comentários a respeito do cogito, aos estudos de A. Koyré. Este artigo levanta a hipótese de que aquilo que se faz presente na reflexão de Lacan é, na verdade, sob o nome de Koyré, o viés de um diagnóstico da modernidade construído por E. Husserl na análise que promove das ciências europeias. O texto procura ainda esboçar qual poderia ser o sentido dessa indicação.
\end{abstract}

Palavras-chave: Lacan; Husserl; revolução científica; sujeito.

ABSTRACT: In Science and truth, one of the Écrits texts first published in 1966, J. Lacan formulates a thesis destined to have a wide repercussion in his theory: he affirms that the subject of psychoanalysis is the subject of modern science. Lacan places this thesis around the need to recognize the conditions of possibility of the type of discourse inaugurated with S. Freud, and now his analysis, that was already dealing with commentaries on the cogito, refers to the studies of A. Koyré. This paper raises the hypothesis that what is present in Lacan's argument is, in fact, under Koyré's name, the bias of a diagnosis of modernity constructed by E. Husserl in the analysis dedicated by him to the European sciences. The text also seeks to outline the meaning of this remark.

Key-words: Lacan; Husserl; scientific revolution; subject.

\footnotetext{
${ }^{1}$ Uma versão resumida da argumentação aqui apresentada foi inicialmente desenvolvida na primeira parte do comentário ao texto Experiência de perda, de autoria de Maria Letícia de Oliveira Reis. Recebeu o título Experiência e condições de possibilidade - Algumas dimensões da relação entre perda e linguagem na psicanálise e foi enviada para publicação no livro Clinicidade.

${ }^{2}$ Professor de Filosofia da Universidade Federal de Lavras, igmcunha@ hotmail.com

${ }^{3}$ Professora de Filosofia da Universidade Federal de Lavras, leasilveiralea@gmail.com
} 
A taça está para Dionísio assim como o escudo está para Ares; assim, a taça pode ser descrita como o 'escudo de Dionísio'. Aristóteles, Poética 1457 b 16-22

Lacan fornece aquilo que, a seu ver, pode ser pensado como a chave filosófica para a compreensão de como se torna possível a experiência psicanalítica em A ciência e a verdade (1966/1998). Pelo nome de Descartes, é à chamada nova física, inaugurada por Galileu, que ela se refere. Como sabemos, a hipótese central desse texto é a de que o sujeito da psicanálise é o sujeito da ciência moderna. É muito significativo, nesse sentido, que as primeiras palavras de Lacan estejam dedicadas a explicitar que não basta que a divisão do sujeito seja, para o psicanalista, um "fato empírico" (ib., p. 869). Isso quer dizer, exatamente, que algo se passa, não no mero nível da apreensão dos fenômenos (como se ela fosse possível desde um ponto de neutralidade ideal), mas no nível de um acontecimento do pensamento que condiciona a abordagem do inconsciente a partir de um território científico. Pois Lacan defende não ter havido uma ruptura de Freud com o cientificisimo de sua época - pelo contrário: exatamente por se inserir aí é que ele teria sido capaz de fundar a psicanálise (ib., p. 871). Tal acontecimento de pensamento registrase, para Lacan, em torno do cogito, na medida em que ele é um momento do sujeito enquanto correlato essencial da ciência. Ao implicar uma dissociação entre saber e verdade, ou entre conhecimento e certeza, o cogito deve ser tomado como condição de possibilidade da psicanálise. Esta, sustenta o autor, é marcada essencialmente pelo cientificismo que resulta da dissociação entre saber e verdade produzida pela ciência moderna e expressa metafisicamente no cogito. A divisão do sujeito que a psicanálise conduz ao centro de sua reflexão é, ele o diz, uma divisão entre saber e verdade e a leitura de Descartes lhe teria permitido situar a questão com esses termos (ib., p. 870) porque é com a suspensão de todo saber prévio que se alcança, na reflexão metafísica, a indicação da verdade sob a forma subjetiva da certeza. O sujeito é um "correlato antinômico" (ib., p. 875) da ciência porque esta, por definição, não pode eliminar a ruptura (entre saber e verdade) que a própria concepção do sujeito, assim tornada possível, expressa.

Não se trata aqui, para Lacan, de responder, seja afirmativa seja negativamente, à pergunta pela inserção da psicanálise na ciência. Trata-se, isso sim, de indicar que a questão pela cientificidade da psicanálise produz uma modificação que incide sobre a 
própria pergunta por aquilo que faz com que algo seja denominado ciência (ib., p. 877). Também não é o caso de suspeitarmos que Lacan estivesse dizendo que as reflexões de Descartes e de Freud pertenceriam a um mesmo registro. Ou seja, ele não está suprimindo, out of the blue, a distância que separa filosofia e psicanálise. Nesse sentido, ele deixa claro que o sujeito da ciência não se confunde com o sujeito que fala (ib., p. 874) - isto é, não se confunde com esse lugar de conjunção entre corpo e enunciação - nem, tampouco, com o sujeito que sofre (ib., p 885), aquele que procura um analista com sua demanda e com sua dor. Mas, se é assim, se o sujeito de que se trata na psicanálise é um sujeito encarnado, e se essa relação ao corpo justamente falta no sujeito da ciência moderna, o que Lacan pretende dizer ao sustentar que este é o sujeito da psicanálise? O que ele está dizendo com isso é que a metafísica implicada na física moderna produz uma dissociação entre saber e verdade e que essa dissociação é o que permite enxergar, a partir de dentro mesmo de uma determinada tentativa de construção de um saber (tentativa cientificista, como foi a de Freud), que uma posição de sujeito resta simultaneamente alijada de e produzida por esse mesmo saber. Ainda: que a psicanálise encontra nesse gesto do pensamento a condição de possibilidade de sua pretensão (intrinsecamente paradoxal) de se constituir como saber a respeito dessa dissociação na medida em que ela se articula num corpo como lugar de desejo $e$ de pulsão. Isso confere ao inconsciente, como objeto, uma posição paradoxal na ciência, já que ele viria dessa verdade por ela mesma desalojada. Do ponto de vista da psicanálise, a verdade que a ciência moderna exclui de modo a poder formular proposições subordinadas a critérios de quantificação e de universalidade é uma verdade investida no sujeito, porém no sujeito do inconsciente. Dessa verdade, a ciência nada quer saber (ib., p. 889). Para Lacan, essa verdade opera como causa material desse sujeito, sendo a consideração do significante como matéria o que lhe autoriza formular isso.

$* * *$

A estrutura argumentativa que permitiria captar o sentido dessa dissociação entre saber e verdade - verdade que restará não sabida como causa do sujeito - não é, no entanto, fornecida por Lacan no texto de 1966 e precisa ser reconstruída. Uma pista 
importante nessa direção nos é fornecida quando Lacan nomeia seu "guia" a esse respeito porque ele se chama Alexandre Koyré (ib., p. 870).

Não há nada de peculiar em destacar esta pista. Todo leitor de A ciência e a verdade sabe que, ao remeter a psicanálise à separação entre saber e verdade, Lacan a está remetendo não apenas à estratégia metódica da dúvida que se desvencilha de qualquer saber tético e da qual resultará algo indubitável, mas, crucialmente, à tese de Koyré em torno da natureza da revolução científica do século XVII, tese que localiza o sentido maior desta revolução na estratégia de matematização da natureza e em suas consequências: princípio da relatividade do movimento, princípio de inércia, destruição do cosmo em favor de um universo sem centro, homogeneizado ontologicamente e concebível como infinito (Koyré, 1943/1982). O que não se costuma explicitar, por outro lado, quando se trata de compreender o ponto central de A ciência e a verdade, é que jaz em Husserl (e, por seu intermédio, nas leituras que os neo-kantianos fizeram de Galileu) a origem da inspiração de Koyré ${ }^{4}$. É nisso que reside, do ponto de vista da discussão ora proposta, a importância da pista.

Aquilo que Husserl defende nos textos compilados sob o título A crise das ciências europeias e a fenomenologia transcendental (1954/1976) é que a ciência moderna, com seu teor naturalista e objetivista, dá lugar a uma alteração do conhecimento - na relação do ser humano com a verdade - na mesma medida em que a técnica se desenvolve em toda a sua potencialidade pelo motivo de ser aqui respaldada pelo cálculo. Um cálculo cego, afinal; pois o preço pago pela ciência para se tornar conhecimento exato e quantitativo a respeito do mundo sensível foi, aos olhos de Husserl, perder de vista a dimensão da experiência intuitiva do mundo da vida. O surgimento de uma nova filosofia da natureza teria sido engendrado, sobremodo, pela distinção entre qualidades primárias (propriedades matemáticas) e qualidades secundárias (apenas indiretamente matematizáveis). Essa distinção, sendo geminada à própria possibilidade da nova física, é o instrumento de uma manobra que relega o que é próprio à experiência subjetiva à condição de mero epifenômeno do tecido da extensão. Esta, de natureza quantitativa, então tomada como aquilo que seria efetivamente real (átomos, corpúsculos, partículas em movimento). Há, assim, para Husserl, algo que se perde de um modo essencial com a

\footnotetext{
${ }^{4}$ De Gandt (2004) expõe a filiação do pensamento de Koyré ao de Husserl.
} 
racionalidade da nova física, fato constitutivo da crise própria à modernidade, momento e lugar conceitual que teria tornado possível o advento da psicologia empírica (ou psicofísica) e de seu objeto: o sujeito visado a partir do "objetivismo" da ciência moderna. No vocabulário da fenomenologia, isso que se perde é o "mundo da vida" [Lebenswelt] e diz respeito ao sujeito, a algo que lhe concerne de uma maneira verdadeira, embora não calculável. O naturalismo e o objetivismo ignorariam a exigência lógica do fundamento absoluto, assim como ignorariam - em decorrência de seu foco na técnica e no cálculo a natureza ontológica desse fundamento ${ }^{5}$.

Vejamos a argumentação de Husserl, em especial no $§ 9$ da Krisis, intitulado "A matematização galilaica da natureza", a fim de melhor delinear os contornos do que ele caracteriza como sendo o "sujeito moderno" (ao mesmo tempo a descoberta da subjetividade, com o cogito cartesiano como fundamento metafísico da física e sua deturpação "psicologizante", ao ser tratado como uma res própria ao "objetivismo" da ciência) para, posteriormente, podermos indicar sua possível presença no "sujeito da ciência moderna" de A ciência e a verdade .

Se, para o platonismo, estava em jogo pensar uma participação, meramente aproximativa, do real no ideal que promovia a possibilidade de uma aplicação da geometria à realidade, para a ciência galilaica é a própria natureza que se encontra matematizada e, enquanto tal, idealizada. Com a nova ciência, a natureza passa a ser tomada como uma multiplicidade matemática e não mais como conjunto de qualidades sensíveis, cujas implicações são, de todo, decisivas; notadamente, pelo fato de que, nesta alteração fundamental, radica a constituição do sujeito moderno como uma espécie de subproduto da unificação dos entes por meio de sua planificação como índices da "verdadeira objetividade": a multiplicidade matemática.

Galileu teria se valido da "evidência" de que a geometria e a matemática nos apresentam a possibilidade de construir idealidades relativamente às figuras puras. Esse

\footnotetext{
${ }^{5}$ Cf. Prado Jr., 1976, p. 169.

${ }^{6} \mathrm{Na}$ tradução para o português, Diogo Ferrer (Husserl, 1954/2012) optou por "obviedade" para traduzir Selbstverständlichkeit (p. 17); a tradução francesa verte o termo alemão por évidence, embora este termo deva traduzir mais diretamente, o alemão Evidenz. De todo modo, cabe destacar o sentido filosófico
} 
campo de idealidade garantiria que temos um mundo por referência apesar dele nos ser dado na experiência sensível cotidiana de forma subjetivo-relativa; apenas o modo de aparecer, de um mundo que é o mesmo, seria divergente para cada um de nós. O que estava implicado nessa "evidência" e que outras "evidências" se somam a ela? A imaginação, argumenta Husserl, só pode "transformar formas sensíveis em outras formas sensíveis" segundo uma gradação em torno de um tipo puro, de modo que o aperfeiçoamento imaginável das formas sensíveis aponta para formas-limite que se tornaram um legado da humanidade graças a um método de idealização e de construção elaborado historicamente e cujo uso implica uma socialização intersubjetiva do espaço.

O método geométrico pré-galilaico de determinação dessas formas ideais remete, segundo Husserl, ao método da agrimensura e, de modo geral, à mensuração, cuja arte descobre, de modo prático, a possibilidade de escolher como padrão de medida certas formas empíricas fundamentais - ou seja, formas sensíveis transmutadas em outras formas sensíveis pela imaginação. Quando esse interesse prático se transformou em interesse puramente teórico, "a arte da medição empírica, com sua função objetivadora empírico-prática, foi idealizada e converteu-se, então, no procedimento do pensar puramente geométrico (...).” (Husserl, 1954/1976, p. 33). Galileu encontrou, assim, já uma geometria pensada como "meio para a técnica", aplicada mediante a subordinação aproximada das formas sensíveis da experiência cotidiana à idealidade das formas-limite. Em outras palavras, a arte empírica da medida teria sido uma espécie de idealização intermediária para a instituição do "pensamento puramente geométrico", preparando, assim, a via para Galileu, i.e., para uma geometria absolutamente universal e seu 'mundo' de puras formas-limite" (ib., p. 33). O espaço geométrico não seria mais um espaço “imaginado", mas construído segundo a razão (ib., p. 29).

Segundo o diagnóstico da Krisis, então, com Galileu, se inicia uma revolução, no sentido de uma inversão do procedimento cognitivo, segundo a qual a referência “objetiva" de nossos pensamentos passou a ser uma idealidade à qual o mundo subjetivorelativo, o mundo da vida, teria de se aproximar indefinidamente; em outras palavras,

decisivo que o termo tem para Husserl no contexto da Krisis: seu diagnóstico pretende, dentre outras coisas, indicar exatamente o quanto certas "evidências" (Selbstverständlichkeiten) que se instauraram na história do pensamento moderno constituem os pressupostos não analisados, e muito pouco explicitados, desta mesma história e que, por isso mesmo, revelam, a contrapelo, o caráter insatisfatório da pretensa “objetividade" nelas fundamentadas (Husserl, 1954/1976, p. 87). 
com Galileu, teria ocorrido tanto uma matematização "direta" das formas sensíveis, quanto uma matematização "indireta” das próprias qualidades sensíveis. Esse platonismo renovado (ib., p. 12 e ss.) faria nascer um ideal de conhecimento rigoroso, com Descartes e depois dele, como uma mathesis universalis cujas consequências seriam particularmente catastróficas para a compreensão da subjetividade.

Segundo esse diagnóstico de Husserl, a geometria, tomada na ingenuidade da evidência apriorística, determina o pensamento de Galileu e o conduz à ideia de uma nova física, uma física cujo objeto, o que há de "objetivo", é uma multiplicidade matemática e não mais o mundo da vida subjetivo-relativo da experiência cotidiana, de tal sorte que, nesta matematização da natureza, o conhecimento racional deixa de ter "sentido" para o homem e para sua experiência pré-científica do mundo. Partindo da ideia de que a geometria favorecia uma determinação unívoca do mundo, Galileu teria procedido ao raciocínio de que esse método teria a capacidade de alcançar uma verdade não-relativa, de promover o conhecimento de um ente verdadeiro em si mesmo, de sobrepujar a relatividade das apreensões subjetivas, relatividade intrínseca ao mundo da intuição empírica. No entanto, essa geometria pura, diz Husserl, só se relaciona com o mundo corporal mediante uma abstração uma vez que, concretamente, as formas reais e possíveis nos são dadas na intuição empírica sensível como "“formas' de uma 'matéria", o que significa que seriam formas de um plenum: o contínuo das qualidades sensíveis.

O que está em jogo aqui é, então, um duplo procedimento de matematização da natureza. Ainda em Galileu, tal procedimento teria de enfrentar uma notável dificuldade relacionada às qualidades sensíveis - ou seja, àquilo que, na experiência pré-científica da natureza, vivenciamos como "cores, sons, odor" (ib., p. 35) -, de tal modo que, se as formas "imperfeitas" do mundo circundante ainda podiam ser tomadas, por uma gradação e aproximação infinitas, a partir das formas puras da geometria, aqueles preenchimentos materiais que integram concretamente os corpos, por sua vez, não parecem, à primeira vista, passíveis da mesma operação; ou seja, tais qualidades não se apresentam como “diretamente" matematizáveis. No entanto, se o telos ${ }^{7}$ imanente desta revolução galilaica

\footnotetext{
7 Cabe destacar que o telos propriamente dito da modernidade, para Husserl, seria a descoberta da "verdadeira subjetividade" com a fenomenologia transcendental (cf., por exemplo, § 26 Krisis, notadamente, p. 113). No entanto, se o vocabulário pode ajudar na compreensão da interpretação da Krisis, por analogia, não será despropositado falar da instauração da física moderna, especialmente de seu "objetivismo", como um telos a partir do qual podemos interpretar a revolução galilaica.
} 
está numa nova física, numa física matemática da natureza, cujo ganho residiria exatamente na substituição de uma física aristotélica das qualidades por uma "objetividade" matemática segundo a qual só deve haver um mundo "por detrás" das aparências apreendidas na experiência subjetiva e relativa do mundo da vida, então se impunha a tarefa de uma matematização radical.

A solução de Galileu, sustenta Husserl, é supor que as qualidades sensíveis, que são descartadas pela abstração e que não são relacionadas diretamente a uma idealidade construtível infinitamente, devem se tornar indiretamente matematizáveis: tudo o que aparece como real nas qualidades sensíveis deve possuir seu "índice matemático" relativamente às formas (já idealizadas com a matematização "direta" da natureza); em outras palavras, tudo se passa como se esta remissão do fluxo da experiência subjetiva e relativa a um "índice matemático" indicasse que as qualidades sensíveis não seriam senão o resíduo psicológico do verdadeiro mundo objetivo, esse mundo de "objetividades ideais determináveis de modo metódico e absolutamente unívoco" (ib., p. 37). A "matematização indireta" da natureza foi, assim, a solução para a exigência de que também as qualidades sensíveis se submetam àquilo a que são arredias: as "formas puras" da matemática. Precedida pela matematização "direta" das formas sensíveis, ao "postular" a "unicidade" do mundo objetivo das multiplicidades matemáticas, foi ela o que, no final das contas, tornou possível uma ciência quantitativa da natureza (por garantir a "unicidade" de uma multiplicidade matemática para um mundo que, doravante, seria complacente à previsão das "hipóteses" científicas) e, consequentemente, a instauração do modo pelo qual a "objetividade" da ciência moderna irá tomar o "sujeito" como correlato desta mutiplicidade matemática. Por esta via, ao mesmo tempo em que o sujeito se põe, com Descartes, como condição metafísica da física, seu tratamento será enviesado por esta mesma física, por seu "objetivismo", de tal modo que a "verdadeira subjetividade" permanecerá apenas latente até o advento da fenomenologia transcendental.

Assim, para que seja possível conhecer o mundo cientificamente, torna-se necessário elaborar um método que, na verdade, o construa sistematicamente. Como a ciência galilaica faz isso? Em primeiro lugar, ela cria uma totalidade infinita de objetividades ideais determináveis de maneira unívoca e decidida a priori. Essa infinidade de objetos é pensável “(...) precisamente por ser construtível ex datis no seu 
ser-em-si objetivamente verdadeiro, pelo seu método que não é somente postulado, mas efetivamente criado, um método de produção apodítica." (ib., p. 38) Em segundo lugar, o cálculo permite alcançar um conhecimento da realidade da intuição que é um conhecimento por "aproximação às idealidades que são próprias à matemática" ( $i b .$, p. 38). As coisas que se apresentam à nossa intuição empírica são res extensae e, sobre elas, a humanidade se tornou a partir daí capaz de fazer uma antecipação indutiva de natureza completamente nova: pode agora calcular, a partir dos dados conhecidos, aqueles que são desconhecidos.

Assim, o diagnóstico husserliano parece já nos indicar uma consequência decisiva do platonismo "renovado" de Galileu: o processo de matematização da natureza, notadamente a matematização "indireta" mencionada acima, garantiria a unicidade do mundo - como mera multiplicidade matemática - que, por sua vez, tornaria possíveis as "hipóteses" com as quais podemos operar "objetivamente" na construção do conhecimento. Desse modo, Husserl já começa a indicar um dos elementos fundamentais - senão o mais importante - para a "crise" oriunda e própria da modernidade (da qual somos os herdeiros). Afinal, esse mundo objetivo da multiplicidade matemática, passível de ser visado e recortado por meio de "hipóteses" científicas, não sendo o mundo de nossa experiência cotidiana do relativo-subjetivo, não pode indicar qualquer sentido para o homem e sua consciência pré-científica.

A grande inflexão da ciência moderna seria, então, a seguinte: em vez de a geometria ser aplicada a partir da experiência das formas empíricas, ela passa a ser aplicada a priori. Ela não é mais um meio para uma técnica; ela se converte em método geral para o conhecimento das realidades "objetivas" de um mundo tomado meramente como multiplicidade matemática.

Como se vê, segundo o diagnóstico de Husserl, a "crise" moderna tem muito pouco a ver com a eficácia da ciência, com seus resultados técnicos ${ }^{9}$, mas está relacionada, antes, com a perda de sentido que essa ciência implica. Perda de sentido na medida em que seus resultados não têm mais nada a dizer sobre a experiência cotidiana e pré-científica que temos no "mundo da vida" e que, por assim dizer, instauram um "novo" sujeito. Em outras palavras, o advento da ciência moderna funda uma cisão sub-reptícia (porque não

\footnotetext{
${ }^{8}$ Cf. o item b do $\$ 9$.

${ }^{9} \mathrm{Cf}$. os parágrafos 1 e 2 .
} 
reconhecida imediatamente segundo as "evidências" e "prejuízos" próprios à modernidade) entre o mundo da vida e a objetividade científica. A ciência moderna produz uma subjetividade concernida com um mundo de "objetividades ideais" que não fazem sentido para sua experiência cotidiana, no "mundo da vida", no qual as coisas são mais ou menos retas, mais ou menos curvas. Mais ainda, no desdobramento desta revolução, posterior a Galileu e Descartes, esse sujeito será analisado, segundo os preceitos próprios a essa "objetividade ideal", enquanto mecanismo de memória, associação de ideias etc.; ou seja, ele se torna objeto de uma psicologia empírica. Reduzida a uma instância psicológica a ser codificada apenas por uma psicologia empírica, a subjetividade foi tomada pelo "objetivismo" moderno como um "subproduto" de seu método; porém, na medida mesma em que esta consideração não é mais do que uma das "evidências" daquele "objetivismo", acaba por lhe escapar sua espessura “egológica” mais fundamental ${ }^{10}$. Desta cegueira própria à “objetividade ideal”, resulta a crise de sentido que acompanharia a história da modernidade e a falta de clareza quanto ao estatuto da subjetividade contida no cogito cartesiano.

É bem verdade que, nos desdobramentos histórico-conceituais do diagnóstico proposto por Husserl, a filosofia transcendental, em particular aquela de Kant, constitui a primeira tentativa de superação desta situação, exatamente mediante o esforço de nuançar a diferença e a tensão entre o eu psicológico (tal como considerado a partir do "objetivismo" da ciência moderna, particularmente pela psicologia empírica) e uma egoidade transcendental anterior à objetividade científica que, exatamente por isso, teria por função fundá-la. De todo modo, não deixa de ser sintomático o fato de que a instauração da ciência matemática da natureza com Galileu e Descartes é quase paradoxal na medida em que instaura um sujeito que deveria ser o fundamento, o solo apodítico a partir do qual a "objetividade científica" poderia se instituir, mas que, ao mesmo tempo, não é já, senão, um produto desta mesma “objetividade”. Em outras palavras, embora o cogito indique a descoberta incontornável de uma instância que se põe como condição transcendental da física, já o próprio Descartes teria contribuído para a perda desta

\footnotetext{
${ }^{10}$ Cf. Ribeiro de Moura, 2001a: "A psicologia nunca poderia apreender o 'elemento subjetivo', já que o 'psíquico' que ela circunscreve como seu domínio é apenas a contrapartida abstrata do 'físico', é apenas uma retomada do dualismo cartesiano no qual ela desde a origem se assentou" (p. 214).
} 
descoberta na medida em que o equiparou à multiplicidade matemática do mundo, ao tomá-lo como res $^{11}$.

Para além do fato de que este processo de formalização se intensificou com a própria aritmetização da geometria, com Leibniz e Newton, e que o "cálculo" veio a impor drasticamente um esvaziamento de sentido em favor de um pensamento confinado a tomar o mundo como "objetos em geral” (Husserl, 1954/1976, pp. 51-2) - inclusive o próprio sujeito -; o que é espantoso, ainda segundo Husserl, é o fato de que a ideia de ciência em Galileu é uma hipótese e uma hipótese muito peculiar, uma vez que sua confirmação se daria por um processo "infinito de confirmações” (ib., p. 48). Além disso, mais espantoso ainda seria o fato de que este "processo infinito de aproximação" (ib., p. 49) a um saber final e absoluto - que, enfim, englobaria a totalidade do real na "objetividade" da exatidão matemática - permaneceu como um pressuposto não questionado ao longo da modernidade na exata medida em que a subjetividade, que é sua condição, permaneceu enfocada apenas a partir da "objetividade" científica e, portanto, tomada, equivocadamente, como mero sujeito psicológico, como uma res. Em outras palavras, ao se colocar como tarefa infinita, essa roupagem dos símbolos mascara o mundo da vida de tal modo que faz com que tomemos pelo verdadeiro ser aquilo que é um método (ib., p. 60), método a ser, então, estendido a qualquer projeto de descrição racional do mundo, inclusive para o tratamento daquilo que, a princípio, deveria ser seu fundamento, a subjetividade transcendental: essa teria sido a tarefa paradoxal da psicologia moderna e, por isso mesmo, a razão de seu fracasso.

Nos desdobramentos posteriores ao parágrafo 9 da Krisis, Husserl enfatiza, pelo menos, duas consequências decisivas desse pressuposto para o tema da constituição da subjetividade moderna: em primeiro lugar, a doutrina segundo a qual as qualidades sensíveis não são, senão, modulações psíquicas do "verdadeiro" mundo objetivo; em segundo, como o sujeito foi reduzido, por conta do método objetivo da ciência, a um elemento desta multiplicidade matemática que dá unicidade ao único mundo objetivo que a razão deveria considerar, então a psicologia só pôde se apresentar como uma

\footnotetext{
${ }^{11}$ Cf. o $\$ 18$ da Krisis e Ribeiro de Moura, 2001a: "Se Descartes é o iniciador da 'verdadeira filosofia', é apenas quanto ao 'começo do começo'. Na verdade ele se detém na 'entrada' da filosofia transcendental, para a qual, entretanto, ele abriu o caminho. E o balanço geral de Husserl será severo: Descartes representa um 'desastre', na medida em que o 'dualismo' determina e extravia o futuro, fazendo com que, 'durante séculos', ninguém se pergunte se, em relação à esfera egológica, um 'exterior' poderia ter algum sentido." (p. 212)
} 
“antropologia psicofísica” (ib., p.72). Os sintomas desta ambiguidade própria ao processo de naturalização do psíquico que atravessa a modernidade filosófica podem ser indicados nas várias tentativas de "investigação sobre o entendimento humano" ou "críticas da razão" (ib., p.72) que lhe são tão caras. De todo modo, ainda que, em alguns momentos, a razão moderna tenha levantado suspeitas acerca desta redução psicofísica da subjetividade, notadamente com a descoberta do cogito por Descartes e com a inflexão transcendental desta descoberta em Kant, a verdadeira subjetividade transcendental nunca teria sido efetivamente desvelada, senão por sua própria (de Husserl) fenomenologia transcendental. Em outras palavras, a viragem do objetivismo científico em direção à subjetividade transcendental (ib., p. 79), a verdadeira subjetividade, significa que a "forma final da psicologia" deverá ser a filosofia transcendental como fenomenologia ( $i b$., p. $82)^{12}$.

O que está em jogo na Krisis, é claro, é bem diferente daquilo que está em jogo na psicanálise. Não só porque, para Husserl, a dimensão perdida envolve, de modo irrevogável e constitutivo, a consciência intencional, mas porque a psicanálise exige a entrada em cena de outra dimensão de subjetividade. Motivos, ademais, convergentes: essa outra dimensão da subjetividade que entra em cena com a psicanálise é aquela que põe em xeque o próprio acesso da consciência a si mesma num registro distinto daquele da fenomenologia transcendental de Husserl. A paradoxal experiência freudiana irá, como sabemos, digladiar-se com o sintoma, com o sonho, com a loucura; irá enfrentar o registro pulsional do que a constitui. Mas isso não nos impede de perceber a existência de um paralelo muito evidente entre, de um lado, saber e verdade, em Lacan e, por outro, técnica e conhecimento no Husserl da Krisis, ou melhor, entre saber e verdade como

\footnotetext{
${ }^{12}$ Cf. Ribeiro de Moura, 1989: "É verdade que o psicólogo, ao exercer a epoché da validade frente aos objetos percebidos, distanciava-se da atitude natural ao dirigir seu interesse aos modos de manifestação (Erscheinungswesen) subjetivos do objeto. Mas ao não exercer uma redução universal, ele permanecia apreendendo a subjetividade como alma, como uma região do mundo, a partir do que era o outro 'prejuízo' da atitude natural que entrava pela porta dos fundos... Se a existência do objeto não interessava em nada à análise do psicólogo, nem por isso ele deixava de apreender esse objeto como um em-si, como um conteúdo distinto das manifestações, situado no exterior da 'região' consciência. (...) Ora, é essa contraposição entre mundo e representação, que caracteriza a psicologia e a atitude natural, que a epoché transcendental vai colocar em questão.” (pp. 166-7)
} 
distinção que institui o "sujeito da ciência moderna" com a oposição entre o "objetivismo" da ciência matemática da natureza e a subjetividade transcendental, na medida em que, em ambos os casos, parece haver a denúncia de um encobrimento da subjetividade que se revela, desde seu nascimento, numa espécie de crise constitutiva da qual a psicologia empírica parece ser o sintoma mais evidente; psicologia que, de um modo ou de outro, deve ser superada em direção a algo distinto daquilo que essa psicofísica poderia revelar. Algo que, para Lacan, acenaria para o lugar da psicanálise enquanto que, para Husserl, indicaria a necessidade da fenomenologia transcendental.

Este paralelo, aliás, encontra eco no fato de Descartes ser visto por ambos os autores como alguém que, após ter tido uma intuição fundamental, recuou dela ${ }^{13}$. Pensamos ser possível defender a partir dessas diretrizes mínimas que, mais do que Koyré, é Husserl quem nos permite compreender um pouco melhor o que está em jogo quando Lacan afirma coisas tais como “(...) a forma lógica dada a esse saber [o da ciência moderna] inclui a modalidade da comunicação como suturando o sujeito que ele implica." $(1966 / 1998$, p. 891)

Lacan sinaliza insistentemente que a "forclusão" efetivada pela ciência moderna mobiliza dois pilares. A exclusão da verdade relativamente ao saber, exclusão em que ela se identifica com o lugar de causa, exige da psicanálise (sempre paradoxalmente) uma forma de visar o sujeito e uma forma de visar o objeto.

Com relação ao primeiro, Lacan insiste em que o sujeito inerente à ciência moderna, que é o sujeito da psicanálise, rompe com qualquer referência humanista (ib., p. 871), o que significa, entre outras coisas, que não se submete a nenhuma estratégia de psicologização (ib., p. 874). É o estruturalismo que torna esse sujeito pensável para a psicanálise exatamente porque é ele que traz à tona a possibilidade de compreender o funcionamento do significante como causa material. É claro que isso acarreta um enorme

\footnotetext{
${ }^{13}$ Cf. o $\$ 18$ da Krisis, especialmente a p. 93, e Lebrun, 2006: "Husserl jamais perde a ocasião de proclamar sua admiração pelo pai fundador do 'subjetivismo transcendental' e pelo 'novo tipo de filosofia' inaugurado pelas Meditações (...). [porém] Se Descartes descobre o ego cogito e se ele se interroga acerca da natureza desse ego, é para responder: 'mens sive animus sive intellectus', quer dizer, para interpretá-lo como um 'residuum do mundo', um 'fragmento do mundo'." (p. 253) Quanto a esse ponto em Lacan, cf. os parágrafos seguintes.
} 
problema, uma vez que os estruturalismos tendem a negligenciar, ou mesmo suprimir, a subjetividade (nisso, acompanhando estritamente, diga-se de passagem, o ideal da ciência moderna). Por isso, Lacan afirma que o sujeito está numa "exclusão interna" relativamente ao objeto ${ }^{14}$ do estruturalismo (ib., p. 875), que obviamente é a linguagem. Se é assim, não restará ao psicanalista outro encaminhamento a não ser tomar o sujeito como ponto de desaparecimento diante do significante. É a esse preço que o sujeito pode, no registro da psicanálise, ser ao mesmo tempo mantido e despsicologizado. À luz disso devemos compreender as referências de Lacan a Descartes no final do seminário 11 - ou seja: naquelas lições que ele diz expressamente estar tomando como ponto de partida para A ciência e a verdade e nas quais lemos, por exemplo, que o erro de Descartes foi tentar fazer da certeza um saber, isto é, "não fazer do eu penso um simples ponto de desvanecimento" (Lacan [1964]1973, p. 204). A psicanálise só se torna possível "certo tempo depois da emergência do sujeito cartesiano" (ib., p. 47) porque, essa referência à subjetividade, o Ocidente a deve a Descartes, e não a Freud, tendo cabido a este efetuar aí um deslocamento: "Não digo que Freud introduz o sujeito no mundo - o sujeito como distinto da função psíquica, a qual é um mito, uma nebulosa confusa - uma vez que é Descartes quem faz isso. Mas direi que Freud se endereça ao sujeito para lhe dizer o seguinte, que é novo - Aqui, no campo do sonho, estás em casa (...).” (ib., p. 45) À psicanálise importa acompanhar o filósofo na introdução do sujeito desde que possa indicar que: 1- esse sujeito possui uma consistência mínima como ponto de enunciação cujo lugar se repete, mas que não reflete nenhuma substância; 2- que o sujeito cuja introdução se trata de reconhecer na modernidade a partir do fato dele ser excluído pela ciência não corresponde a um ideal de transparência do eu em relação a si mesmo, mas está implicado nas formações do inconsciente; 3- a respeito desse sujeito, consequentemente, não se pode construir um conhecimento conforme o modelo então assumido para o que se pretende que seja conhecimento.

A despeito dessas indicações, um leitor não familiarizado com o pensamento lacaniano talvez venha se perguntando algo como: não seria de se esperar que a psicanálise virasse as costas para o cogito, esse ponto originário da filosofia da

\footnotetext{
${ }^{14}$ Esta sentença costuma ser lida como se Lacan estivesse aí dizendo que o sujeito está numa relação de exclusão interna ao objeto $a$. Basta retomar o movimento do texto para concluir pela impossibilidade de uma tal leitura.
} 
consciência ? $^{15}$ Por que Descartes se torna necessário para Lacan? O sujeito do inconsciente é, para o psicanalista, o cogito não tanto porque as proposições da ciência moderna, ao serem formuladas sob o ideal de universalidade, exijam uma subjetividade formal "purificada de todo conteúdo e substância"16 , mas porque um pensamento implica, a seu ver, um lugar a partir do qual se pensa, ainda que tal pensamento seja inconsciente. Tal lugar, concebido a partir da estrutura da linguagem e da noção de significante é o que Lacan chama de "sujeito"17. O que é universal aqui é apenas a ideia de "lugar" e a forma pela qual ele se estrutura e se repete. Que se fale, isso implica: 1- o direcionamento de um corpo ao campo da linguagem; 2- um lugar de alteridade radical, que Lacan nomeia "Outro"; 3- a divisão daquele que fala entre je e moi; 4- a tentativa de imaginarizar o interlocutor; 5- a inserção do desejo numa fantasia que circunscreve o lugar vazio do objeto; 6- o investimento da fala por um movimento pulsional. Esse lugar, marcado nessa estrutura (chamada por Lacan ([1960]1966/1998) de "grafo do desejo"), manifesta-se com aquela certeza paradoxal que é experimentada com as formações do inconsciente.

O outro pilar daquilo que é excluído pela ciência moderna é a forma de visar o objeto. O modo de sua consideração não poderá ser desvencilhado de uma experiência de perda no sentido de ser uma perda daquilo que, para a psicanálise, é fundante de qualquer experiência. A ciência moderna, diz Lacan, produz um objeto cujo estatuto ainda não teria sido elucidado (Lacan, 1966/1998, p. 869). Esse objeto (que Lacan nomeia objeto a) é um objeto de perda; não de uma perda empírica, mas de uma perda desde sempre havida. Para Lacan, a fantasia de se ter perdido um objeto precisa ser reconhecida em seu estatuto de fantasia e, portanto, como algo que já se constitui como defesa. Trata-se de uma defesa contra uma condição mais fundamental de falta - não a falta de um objeto, um objeto que teria sido perdido, mas falta de ser, que antecederia qualquer ideia relacionada a qualquer objeto, seja ele considerado perdido ou não. Quando nos referimos à existência de um corpo, nessa existência, a linguagem já está implicada e a ruptura entre significante e coisa deve contar como prévia àquilo que vai aparecer como existência. Por isso, a condição de perda antecede tanto a noção de objeto quanto o lugar do objeto na fantasia.

\footnotetext{
${ }^{15}$ Essa pergunta é colocada por Dolar (1998) em Cogito as the subject of the unconscious. Nesse texto, o autor apresenta os diversos momentos da reflexão de Lacan sobre o cogito, buscando mostrar quais problemas conduziram a quais inflexões nesse percurso.

${ }^{16}$ Ao contrário do que defende, nesse ponto, Dolar, op. cit., p. 15.

${ }^{17}$ Pelo menos até o momento de escrita de A ciência e a verdade.
} 
A ponderação de uma perda a priori não pode ser transferida para Freud, para quem o objeto é perdido em uma mítica vivência primária cujas premissas são empiristas. $\mathrm{O}$ objeto perdido, que estará em jogo nos processos de identificação, é inicialmente mobilizado por Freud como condição de possibilidade do uso da linguagem - portanto, como condição de possibilidade do sistema Pcs-Cs. São os esforços voltados para o restabelecimento da identidade de percepção mediante a identidade de pensamento (isto é: os esforços para reencontrar o objeto) que conduzem o aparelho a administrar os investimentos de energia de um modo tal que eles não precisem mais ser feitos massivamente; ou seja: direcionando pequenos investimentos a caminhos complexos (processo secundário), em vez de direcionar grandes investimentos a caminhos curtos (processo primário). Esta é, para Freud ([1895]1950/2003 e 1900/2012), uma condição da fala e do pensamento (pré-consciente/consciente), condição que equivale também a uma estratégia de evitamento da alucinação. Diferentemente, para Lacan, aquilo que é importante de se destacar na consideração da perda do objeto é que a perda é simultânea, e não posterior, à inscrição daquilo que Freud nomeia representação e que Lacan trabalha sob o termo "significante". Uma vez que exista linguagem, está dada também a perda de um objeto que insiste sobre o sujeito como causa de seu desejo.

$* * *$

Tratou-se de situar acima, ainda que de maneira breve, o fato de que a psicanálise exige, em virtude de sua relação com a ciência, uma nova forma de visar o sujeito e uma nova forma de visar o objeto. Esse duplo encaminhamento, que toma o objeto (objeto $a$ ) como verdade e como causa de um modo tal que ele funda o saber sem se tornar sabido, é filiado explicitamente, por Lacan, a Koyré. Neste artigo, levantamos a hipótese de que o nome de Koyré trai, na verdade, a presença de Husserl na argumentação de Lacan. O que precisamos perguntar agora, no sentido de conferir um encerramento a esta argumentação, é: mas o que ganhamos ao reconhecer na argumentação de Husserl, mediada por Koyré, a origem da reflexão à qual Lacan procede em A ciência e a verdade?

Fundamentalmente, ganhamos no sentido de aprofundar nossa compreensão das condições de possibilidade da experiência psicanalítica. Isso por um motivo, a nosso ver, muito claro, embora nada simples: quem explicita o que a matematização da natureza 
provoca em termos de subjetividade, levantando a tese de uma maneira inaugural, é Husserl, e não Koyré. É bem verdade que diversos aspectos dessas considerações de Husserl sobre Galileu, Descartes e a ciência moderna estão presentes em Koyré, citado diretamente por Lacan. No entanto, pelo próprio fato de este último estar mais interessado numa história filosófica da ciência e menos num diagnóstico geral da modernidade em vista de seu telos na forma da emergência da subjetividade transcendental a partir da "crise da razão", cabe destacar que pelo menos um destes elementos não é retomado e tematizado explicitamente por Koyré, a saber, o tema da subjetividade nos termos da análise de Husserl - a despeito de sua dívida intelectual para com este último. Afinal, é em Husserl, e não em Koyré, que encontramos a tese tão emblemática quanto indicativa segundo a qual a modernidade, a um só tempo, carrega uma descoberta e um encobrimento (Husserl, 1954/1976, p. 62): a descoberta da subjetividade a partir do cogito cartesiano e, mesmo em Descartes, o encobrimento desta subjetividade a partir de seu tratamento pela ciência para a qual ela deveria servir de fundamento ${ }^{18}$. Assim, o "sujeito da ciência moderna" pode se ser lido a partir de uma ambiguidade notável: o fundamento que constitui a ciência moderna e que ela deveria pressupor e, ao mesmo tempo, sua interpretação "objetivista" como contraparte desta mesma ciência, apenas um "resíduo" a ser focado segundo os procedimentos desta mesma ciência. Donde a psicologia moderna ser o sintoma mais claro, para Husserl, desta perda de sentido imposta pela matematização da natureza e a consequente instauração da nova física a partir de Galileu.

Assim como as "propriedades secundárias", a dimensão inconsciente da experiência humana é algo que o discurso da ciência, por definição, não pode apreender diretamente, senão distorcendo-o inteiramente. Se o primeiro aspecto situa a psicologia no centro de um impasse, o segundo o faz com a psicanálise, lugar em que o impasse é positivado, assumido enquanto tal. As consequências são distintas em cada caso e precisam ser exploradas em suas respectivas especificidades. Mas poderíamos talvez dizer que aquilo que está perdido para o sujeito é constitutivo de suas relações com os

\footnotetext{
${ }^{18}$ Cf. Ribeiro de Moura, 2001b: "Os elogios de Husserl a Descartes são invariavelmente seguidos de críticas (...). É que, aos olhos de Husserl, a decodificação cartesiana da pergunta pela possibilidade do conhecimento era vinculada à transformação da significação 'mundo' feita por Galileu. Ao considerar o mundo a partir da geometria, Galileu abstraía dele tudo que se referia aos sujeitos, e era dessa abstração que resultavam as 'puras coisas corpóreas' (...). A revolução galileana não se limitava assim a fundar uma nova física: sob o fundo da nova concepção de natureza é a própria significação 'mundo' que se altera e o dualismo cartesiano que se antecipa." (p. 164)
} 
outros e com o mundo de um modo "êxtimo" ou unheimlich, ou ainda, se quisermos, ao modo de uma alienação imanente cuja explicitação é tornada possível por algo que se passa na configuração ontológica da ciência moderna e que destina à experiência que é a nossa uma natureza de crise (nos termos de Husserl ${ }^{19}$ ) ou de paradoxo (nos termos de Lacan). O paralelismo aqui ensaiado visou menos a indicação de um parentesco conceitual e, muito mais, uma semelhança de família ${ }^{20}$ em torno de uma problemática mais ou menos comum. A se crer na definição de analogia do velho Aristóteles, segundo a qual o que é equacionado num raciocínio analógico não são propriamente os termos, mas duas relações entre quatro termos distintos, então, talvez, não seja precipitado dizer, feitas as contas, que entre A ciência e a verdade e o diagnóstico husserliano da modernidade vai a distância de dois projetos análogos, pelo menos no que diz respeito a alguns de seus elementos centrais.

\footnotetext{
${ }^{19}$ Onde possui, é claro, um sentido próprio, vinculado ao destino moderno do saber europeu. O caráter etnocêntrico do argumento de Husserl é problematizado por Prado Jr., op. cit.

${ }^{20}$ É impossível não nos remetermos aqui ao provocativo e irônico artigo de Lebrun intitulado: "David Hume no álbum de família de Husserl".
} 


\section{REFERENCIAS}

DE GANDT, F. (2014) Husserl et Galilée - Sur la crise des sciences européennes. Paris: Vrin.

DOLAR, M. (1998) “Cogito as the subject of the unconscious”. Em: Zizek, S. Cogito and the unconscious. Durham and London: Duke University Press.

FREUD, S. (1900). A interpretação dos sonhos. Volume 2. (Trad.: R. Zwick) São Paulo: L\&PM, 2012.

FREUD, S. ([1895]1950). "Projeto de uma psicologia" (Trad.: O. F. Gabbi Jr.). Em: Gabbi Jr., O. F. Notas a Projeto de uma Psicologia: As origens utilitaristas da psicanálise. Rio de Janeiro: Imago, 2003.

HUSSERL, E. (1954) La crise des sciences européennes et la phénomenologie transcendentale. (Trad.: G. Granel). Paris: Gallimard, 1976.

HUSSERL, E. (1954) A crise das ciências europeias e a fenomenologia transcendental. (Trad. Diogo Ferrer). Rio de Janeiro: Forence Universitária, 2012.

KOYRÉ, A. (1943) “Galileu e Platão”. Em: Estudos de história do pensamento científico. Rio de Janeiro: Forense Universitária, 1982, pp. 152-180.

LACAN, J. (1960) "Subversão do sujeito e dialética do desejo no inconsciente freudiano". Em: Escritos. (Trad.: Vera Ribeiro) Rio de Janeiro: Zahar, 1998, pp. 807-842.

LACAN, J. (1973) Le séminaire. Livre XI: Les quatre concepts fondamentaux de la psychanalyse (1964). Paris: Éditions du Seuil.

LACAN, J. (1966) "A ciência e a verdade”. Em: Escritos. (Trad.: Vera Ribeiro) Rio de Janeiro: Zahar, 1998, pp. 869-892.

LEBRUN, G. (1982) “David Hume no álbum de família de Husserl” (Trad.: Márcio Suzuki). Em: A filosofia e sua história. São Paulo: Cosac Naify, 2006, p. 253-272.

PRADO Jr., B. (1976) “Os limites da Aufklärung”. Em: Estudos Cebrap número 15. São Paulo: Brasiliense.

RIBEIRO DE MOURA, C. A. (1989) Crítica da razão na fenomenologia. São Paulo: Edusp \& Nova Stella.

RIBEIRO DE MOURA, C. A. (2001a) "Cartesianismo e Fenomenologia". Em: Racionalidade e Crise: Estudos de História da Filosofia Moderna e Contemporânea, São Paulo: Discurso Editorial \& Editora UFPR, pp. 207-235.

RIBEIRO DE MOURA, C. A. (2001b) "Husserl: Significação e existência". Em: Racionalidade e Crise: Estudos de História da Filosofia Moderna e Contemporânea, São Paulo: Discurso Editorial \& Editora UFPR, pp.159-183. 